\title{
The Color of Primary Teeth: A Literature Review
}

\author{
Abu-Hussein Muhamad* and Sarafianou Aspasia \\ Limited to Pediatric Dentistry, 123 Argus Street, 10441 Athens, Greece
}

\begin{abstract}
The purpose of this study was to evaluate the color of primary teeth, and study how to develop a model shade guide for primary teeth. A concise synopsis on color and the esthetics of primary teeth has been obtainable. Young children and their parents' craving for an esthetically amusing smile were pointed out. Fundamental information on mechanisms of tooth color perception, color notation systems, and working ideology of instruments for tooth color measurement were subsequently provided. Issues related to color variety and allocation of primary teeth were underlined in the last section. It was accomplished that color of primary teeth appears to be much more important than conventionally thought. Supplementary research and its scientific function should be measured in order to improve the esthetics of restorations on primary teeth.
\end{abstract}

Keywords: Tooth color; Primary teeth

\section{Introduction}

Young children and their parents' comparable aspiration an esthetically pleasant smile. In fact, children as young as three years of age are capable to discriminate between gorgeous and unappealing peers [1]. Superficial attributes and appearance influence a child's impression of and reaction to other [2]. It was suggested that the need or demand for esthetic dentistry may be extensive based and surpass formulaic perceptions [3]. In a study that assessed dentists' and parents' perceptions of health, esthetics, and treatment of maxillary primary incisors, all groups (dentists and parents) considered incisor steel crowns esthetically unaccepted and unhealthy, although they have been shown to be effective restorations [4]. A total of $83 \%$ of dentists favored no treatment of discolored primary incisors, while $71 \%$ of parents favored treatment. The poor esthetics of anterior steel crowns is evidenced by methods to improve their appearance with composite veneering. Parents articulated concerned about poor esthetics, and children reported being teased; among children aged 9 to 13 years, dental features were the fourth most common reason for teasing after height, weight, and hair [5,6].

\section{Tooth Color Perception}

The phenomenon of color is a psychophysical response to the physical communication of luminosity energy with an object, and the subjective experience of an individual observer. Three factors manipulate the perception of color, namely, the light source, the object being viewed, and the observer viewing the object $[7,8]$.

The color and exterior of teeth is a multifaceted phenomenon, with many factors such as illumination conditions, translucency, opacity, light scattering, gloss, and the human eye and brain influencing the overall perception of tooth color. The color of a tooth is resolute by the mutual effects of inherent and extrinsic colorations $[9,10]$. Intrinsic tooth color is associated with the light scattering and absorption properties of the enamel and dentin. Extrinsic color is linked with the amalgamation of materials (e.g. tea, chlorhexidine, and iron salts) onto the surface of enamel, and in particular the pellicle coating, which ultimately cause extrinsic stain. The color of a tooth is also determined by a combination of its optical properties. When light encounters a tooth, part of it is transmitted and another part is reflected (surface and volume reflection; specular and diffuse reflection). Non-white color is principally a result of assimilation along these path lengths and the absorption coefficient of the tooth tissues [11-13].

\section{Color Notation Systems}

A major problem frequently arises when attempting to communicate colors to others. To this end a number of color scales have been developed. Color can be described according to the Munsell color space in terms of hue, value, and chroma one to distinguish between different families of color, for example, reds, blues, and greens. Value indicates the lightness of a color ranging from pure black to pure white. Chroma describes the strength, intensity of vividness of a color [14-16].

The Commission International de L'Eclairage (CIE), an organization devoted to standardization in areas such as color and appearance, defined in 1931 a standards light source, developed a standard observer, and enable the calculation of tristimulus values, which represent how the human visual system responds to a given color. IN 1976, the CIE further defined a color space, CIE $L^{\star} a^{\star} b^{\star}$, that supports the accepted theory of opponent process. The opponent color theory suggests process [17]. The opponent color theory suggests that there are three opponents' channels: red versus green, blue versus yellow, and black versus white (the latter type is related to rods, achromatic, and detects light, dark variation). Responses to one color of an opponent channel are antagonistic to those to the other color [18].

The CIE L*a $\mathrm{a}^{\star} \mathrm{b}^{\star}$ color space represents a uniform color space, with equal distances corresponding to equal perceived color differences. In this three-dimensional color space, the three axes are $L^{*}, a^{*}$, $b^{*}$. The $L^{*}$ value is a measure of the lightness of an objective and is quantified on a scale such that a perfect black has an $L^{\star}$ value zero, and perfect reflecting diffuser an $\mathrm{L}^{*}$ value 100 . The $\mathrm{a}^{*}$ value is a measure of redness (positive $a^{\star}$ ) or greenness (negative $a^{\star}$ ). The $b^{*}$ value is a measure of yellowness (positive $b^{\star}$ ) or blueness (negative $b^{\star}$ ). The $a^{\star}$ and $\mathrm{b}^{\star}$ coordinates approach zero for neutral colors (white, grays),

*Corresponding author: Abu-Hussein Muhamad DDS, MSC, MSCD, DPD Limited to Pediatric Dentistry, 123 Argus Street, 10441 Athens, Greece, E-mail: abuhusseimuhamad@gmail.com

Received July 21, 2012; Accepted September 24, 2012; Published September 26, 2012

Citation: Muhamad AH, Aspasia S (2012) The Color of Primary Teeth: A Literature Review. Dentistry 2:144. doi:10.4172/2161-1122.1000144

Copyright: (C) 2012 Muhamad AH, et al. This is an open-access article distributed under the terms of the Creative Commons Attribution License, which permits unrestricted use, distribution, and reproduction in any medium, provided the original author and source are credited. 
and increase in magnitude for more chromatic or intense colors. The advantage of the CIE $\mathrm{L}^{*} \mathrm{a}^{\star} \mathrm{b}^{\star}$ system is that color differences can be expresses in units that can be related to visual perception and clinical significance [19].

\section{Dimension of Tooth Color}

The dimension of tooth color is possible via a number of methods including visual assessment with shade guides, spectrophotometry, colorimetry, and computer analysis of digital images. Instruments such as spectrophotometers and colorimeters have been used in industrial and research settings for the measurement of color of a wide range of materials and substrates. Spectrophotometers are most widely used for measuring surface colors. Spectrophotometers measures one wavelength at a time from the reflectance or transmittance of an object, and have been used to measure the visible spectra of extracted and vital teeth [20].

They are repeatedly used for eminence organize and recipe formulation. They can also evaluate metamerism (a pair of specimens match under one set of illuminant and observer conditions, but mismatch under another set of conditions). Colorimeters have color filters that estimated the spectral function of the standards observer's eye and ate generally designed to measure color in $\mathrm{X} ; \mathrm{Y} ; \mathrm{Z}$ tristimulus terms or in CIE $L^{*} a^{*} b^{*}$ values. Much of the dental research on the natural color of teeth in vitro and in vivo has been conducted with colorimeter. Colorimeter measurements have been compared with spectrophotometer readings and deemed reliable and accurate for color difference measurements. In general, colorimeters are easy to use and less expensive than spectrophotometers. However, the instrumental agreement and repeatability of the instrument is poor due to the aging of the detectors (filters) and poor reproducibility of the filters to agree with CIE color matching functions. In additions, the colorimeter cannot be used to quantify metamerism. Another approach for measuring tooth color is via computer analysis of photographic images. This approach has been productively used to evaluate the bleaching effects of peroxide-containing products over time and expressing the color changes in terms of CIE $L^{\star} a^{*} b^{\star}$ values [19-21].

\section{Color of Primary Teeth}

Although color range of human teeth has been reported by numerous investigators, no dependable catalog of tooth color presently exists for the primary dentition. Clark published the first study on color ranges of natural teeth, with the following Munsell H/V/C values: $6 \mathrm{YR}$ to $9.3 \mathrm{Y}, 4$ to 8 , and 0 to 7 respectively. In vivo measurement of maxillary anterior teeth with a colorimeter showed that; 1 ) tooth color was best represented by its middle third, 2) women's teeth in general were lighter, less chromatic, and less reddish colored than men's, 3) aging produced darker and more reddish teeth 4) cuspid teeth were darker than central or lateral incisors, and 5) central incisors had the highest lightness [18-21].

Primary teeth are frequently measured lighter than continuing teeth, but only a few studies on color of primary frontal teeth of 60 Japanese children was evaluated by various measuring devices. Based on these results, the primary anterior tooth surface color was found to be very light. A few shades of are available for restoring primary teeth. In a study measuring parental satisfaction was most often related to the color of the restorations. Color analysis revealed that the colors of the White Steel Crown and Kinder Krown Pedo 1 were substantially different from the color of the primary anterior teeth of Japanese Children. Color analysis also revealed that the colors of esthetic anterior primary crowns were substantially different from the color of the primary anterior teeth of Japanese children. Evaluation of primary teeth color for thee different ethnic groups (AA, C, and $\mathrm{H}$ ) in the United States were among African-American and Hispanic patients). A comparison of four shades from four different shade guides with primary teeth color of African-American, Caucasian, and Hispanic Children revealed significant differences among both shades and ethnic groups $[10,13,15,19,20]$.

\section{Results}

$L^{\star} a^{\star} b^{\star} C^{\star} h^{\circ}$ values for primary teeth were $82.5,0.2,18.3,18.4$, and 89.4 respectively. The most habitually selected shades were A1 (46\%), A2 (25\%), and B2 (11\%). Canines had the highest lightness. Maxillary canines had the lowest $\mathrm{a}^{*}$ values, whereas mandibular primary incisors had the highest $\mathrm{a}^{\star}$ values. Molars were the most chromatic (having the highest $b^{\star}$ values), followed by canines and primary incisors in decreasing order. Coverage error ( $\mathrm{ÄEC} \mathrm{E} \mathrm{COV}{ }^{\star}$ ) of Vitapan Classical was $4.2( \pm 1.9 \mathrm{SD})$ [21-24].

\section{Conclusion}

Color of primary teeth appears to be much more significant than traditionally believed. Supplementary research and its scientific application should be performed in order to improve the esthetics of restoration of primary teeth.

Among primary teeth, the widest ranges, in order, were recorded for: -

\section{- Lightness}

- Chroma

- Hue

Three Vitapan Classical shades were the best match for $82 \%$ of primary teeth. Color differences among the same patient's teeth underline the need for an individual approach in color matching and reproduction of primary teeth.

\section{References}

1. McLaren K (1987) Color space, color scales and color difference. In: McDonald $\mathrm{R}$, editor. Color physics for industry. Huddersfield: H Charlesworth \& Co 97115

2. Patterson $D(1987)$ Instruments for the measurement of the color of transparent and opaque objects. In: McDonald R, (ed.). Color physics for industry. Huddersfield: H. Charlesworth \& Co 35-62.

3. Paravina RD, Powers JM (2004) Esthetics color training in dentistry. St. Louis MO: Elserview-Mosby.

4. Paul S, Peter A, Pietroban N, Hammerle CH (2002) Visual and spectrophotometric shade analysis of human teeth. J Dent Res 81: 578-582.

5. Ishikawa-Nagai S, Sato RR, Shiraishi A, Ishibashi K (1994) Using a computer color-matching system in color reproduction of porcelain restorations. Part 3 A newly developed spectrophotometer designed for clinical application. Int $\mathrm{J}$ Prosthodont 7: 50-55.

6. Macentee M, Lakowski R (1981) Instrumental colour measurements of vital and extracted human teeth. J Oral Rehabilit 8: 203-208.

7. Zhao Y, Zhu J (1998) In vivo color measurement of 410 maxillary anterior teeth Chin J Dent Res 1: 49-51.

8. Russell MD, Gulfraz M, Moss BW (2000) In vivo measurement of colour changes in natural teeth. J Oral Rehabil 27: 786-792.

9. Redmalm G, Johannsen G, Ryden H (1985) Lustre changes on teeth. The use 
of laser light for reflexion measurements on the tooth surface--in vivo. Swed Dent J 9: 29-35.

10. Hasegawa A, Motonomi A, Ikeda I, Kawaguchi S (1999) Color of natural tooth crown in Japanese people. Col Res Appl 25: 43-48.

11. Tung FF, Goldstein GR, Jang S, Hittelman E (2002) The repeatability of an intraoral dental colorimeter. J Prosthet Dent 88: 585-590.

12. Goncalves FA, Birmani EG, Sugaya NN, Melo AM (1998) Natal teeth: review of the literature and report of an unusual case. Braz Dent J 9: 53-56.

13. da Silva CM, Ramos MM, Carrara CF, Dalben Gda S (2008) Oral characteristics of Newborns. J Dent Child (Chic) 75: 4-6.

14. Alvarez MP, Crespi PV, Shanske AL (1993) Natal molars in Pfeiffer syndrome type 3: a case report. J Clin Pediatr Dent 18: 21-24.

15. Anegundi RT, Sudha R, Kaveri H, Sadanand K (2002) Natal and neonatal teeth: a report of four cases. J Indian Soc Pedod Prev Dent 20: 86-92.

16. Rusmah M (1991) Natal and neonatal teeth: a clinical and histological study. J Clin Pediatr Dent 15: 251-253.

17. Chawla HS, Subba Reddy VV (1988) A follow-up study of 25 cases of natal/ neo-natal teeth. J Indian Soc Pedod Prev Dent 6: 57-61.

18. Barfiwala DR (1996) Natal and neonatal teeth: a review of 50 cases. J Indian Soc Pedod Prev Dent 14: 21-23.

19. Anderson RA (1982) Natal and neonatal teeth: histologic investigation of two black females. ASDC J Dent Child 49: 300-303.

20. Singh S, Subbba Reddy VV, Dhananjaya G, Patil R (2004) Reactive fibrous hyperplasia associated with a natal tooth. J Indian Soc Pedod Prev Dent 22 183-186.

21. Delbem AC, Faraco Junior IM, Percinoto C, Delbem AC (1996) Natal teeth: Case report. J Clin Pediatr Dent 20: 325-327.

22. 22El Khatib K, Abouchadi A, Nassih M, Rzin A, Jidal B, et al. (2005) Natal teeth apropos of five cases. Rev Stomatol Chir Maxillofac 106: 325-327.

23. McDonald RD, Avery DR, Dean JA (2004) Dentistry for the Child and Adolescent. (8thedn), Missouri: Mosby.

24. 24Portela MB, Damasceno L, Primo LG (2004) Unusual case of multiple natal teeth. J Clin Pediatr Dent 29: 37-39. 